CLINICAL STUDY

\title{
Systemic ghrelin levels in subjects with growth hormone deficiency are not modified by one year of growth hormone replacement therapy
}

\author{
Joop A M J L Janssen, Fanny M van der Toorn, Leo J Hofland, Peter van Koetsveld, Fabio Broglio ${ }^{1}$, Ezio Ghigo ${ }^{1}$, \\ Steven W J Lamberts and Aart Jan van der Lely \\ Department of Internal Medicine, Erasmus University Medical Center Rotterdam. The Netherlands and ${ }^{1}$ Department of Internal Medicine, \\ University of Turin, Italy \\ (Correspondence should be addressed to Joop Janssen, Department of Internal Medicine, Room D-438, Erasmus University Medical Center Rotterdam, \\ Dr Molewaterplein 40,3015 GD Rotterdam, The Netherlands; Email: janssen@inw3.azr.nl)
}

\begin{abstract}
Objective: Ghrelin stimulates growth hormone $(\mathrm{GH})$ secretion both in vivo and in vitro. Ghrelin is mainly produced in and released from the stomach but it is probably also produced in the hypothalamic arcuate nucleus. Whether pituitary GH release is under the control of ghrelin from the stomach and/or from the arcuate nucleus is not known. Moreover, no data on the feedback of GH on systemic ghrelin concentrations are available. It has recently been suggested that ghrelin may induce obesity.

Design: In this study, we addressed the following two questions: a) are circulating ghrelin levels increased in human $\mathrm{GH}$ deficiency (GHD), and b) does $\mathrm{GH}$ treatment modify ghrelin levels in human GHD?

Methods: The study group consisted of 23 patients with GHD. Eighteen had developed adult-onset GHD and five had developed GHD in their childhood (childhood-onset GHD). Ghrelin was measured with a commercially available radioimmunoassay. All measurements were performed twice, first at baseline, before the start of GH replacement therapy, and then again after one year of therapy. GH doses were adjusted every 3 months, targeting serum total IGF-I levels within the normal gender- and age-related reference values for the healthy population. Maintenance doses were continued once the target serum total IGF-I levels were reached.

Results: The sum of skinfolds and body water increased significantly, body fat mass and percentage body fat decreased significantly and body mass index and waist-hip ratio were not significantly changed by one year of GH replacement therapy.

Before the start of GH replacement therapy, mean value and range for fasting ghrelin in the studied GHD subjects tended to be lower in comparison with healthy subjects in the control group although the difference did not reach significance (GHD ghrelin mean $67.8 \mathrm{pmol} / \mathrm{l}$, range 37.6-116.3 pmol/l; control mean $83.8 \mathrm{pmol} / \mathrm{l}$, range $35.4-132 \mathrm{pmol} / \mathrm{l} ; P=0.11$ ).

One year of GH replacement therapy did not modify circulating ghrelin levels (ghrelin before $\mathrm{GH}$ therapy: $67.8 \mathrm{pmol} / \mathrm{l}$, range $37.6-116.3 \mathrm{pmol} / \mathrm{l}$; after GH therapy: $65.3 \mathrm{pmol} / \mathrm{l}$, range $35.8-112.6$; $P=0.56)$.

Conclusions: We did not observe elevated ghrelin levels in adult GHD subjects and GH replacement therapy did not modify circulating ghrelin levels, despite significant decreases in body fat mass and percentage body fat. It is conceivable that the lack of ghrelin modifications after long-term GH therapy was due to the reduction of adiposity and insulin on one hand, and increased GH secretion on the other. However, it is still possible that systemic ghrelin is involved in the development of obesity, both in normal and GHD subjects.
\end{abstract}

European Journal of Endocrinology 145 711-716

\section{Introduction}

Recently, ghrelin, an endogenous ligand for the growth hormone (GH)-secretagogue receptor was discovered (1). Ghrelin is a 28 -amino acid peptide with an unusual octanoylated serine 3 at the N-terminal end of the molecule which is crucial for its biological activity, at least in terms of GH release (1). Ghrelin stimulates $\mathrm{GH}$ secretion, both in vivo and in vitro. The mechanism of ghrelin's action to stimulate GH secretion seems different to that of GH releasing hormone (GHRH). Surprisingly, ghrelin is produced in and released from the stomach, although it is probably also produced in the hypothalamic arcuate nucleus and several other tissues 
of the body (2). Whether pituitary GH release is under the control of ghrelin from the stomach and/or from the arcuate nucleus is presently unknown (2). Moreover, no data on the feedback of GH on systemic ghrelin concentrations in humans are yet available. Pepck-HGH transgenic mice overexpress the fusion gene coding for human $\mathrm{GH}$ under the transcriptional control of the phosphoenolpyruvate carboxykinase promoter (3). It has recently been shown that these mice have low levels of ghrelin, as compared with normal littermates, due to negative feedback of high GH levels on ghrelin concentrations (3). If such a negative feedback system is also present in humans, one could theoretically expect elevated systemic ghrelin levels in GH deficiency (GHD).

In rats, it has been reported that GHD does not modify ghrelin mRNA expression in the hypothalamus (4). In another study, it was observed that systemic ghrelin administration to normal rats and mice caused weight gain by reducing fat utilization and this effect seemed independent of the effects of ghrelin on GH secretion (5). In accordance with this latter observation, administration of ghrelin or ipamorelin, a GH secretagogue, to GHD animals induced an increase in body weight $(6,7)$.

Human GHD is characterized by alterations in body composition and notably an increase in abdominal fat mass. The animal studies mentioned above open the possibility that ghrelin is also involved in body-weight gain in human GHD. In this study, we addressed the following two questions: a) are circulating ghrelin levels increased in human GHD, and b) does $\mathrm{GH}$ treatment modify ghrelin levels in human GHD?

\section{Subjects and methods}

The study group consisted of 23 patients with GHD who consecutively visited our outpatient clinic. At the start of the study, GHD was diagnosed in all subjects by two separate tests (arginine and GHRH) and defined as a peak GH concentration of less than $5 \mu \mathrm{g} / \mathrm{l}$ across the two stimulation tests, determined by immunoradiometric GH assay (CIS bio international, Gif-sur Yvette, France; intra-assay coefficient of variation (CV) $2.8 \%$, interassay $\mathrm{CV} 4.4 \%$ ). The study population consisted of 13 males and 10 females with a mean age of 48 years (range 17-67 years). Eighteen subjects were known to have had a pituitary tumor and of these 17 had been treated by hypophysectomy. Of the remaining five subjects, four had idiopathic GHD and one had been treated with a dopaminergic agonist because of prolactinoma. In addition, 17 of the 23 subjects had been treated with radiotherapy. Eighteen had developed adult-onset GHD while five had developed GHD at a young age (childhood-onset GHD). Fourteen subjects had three or more pituitary hormone deficiencies other than GHD. All individuals were on stable and optimized replacement therapies with thyroid hormone, hydrocortisone and gonadal steroids, as appropriate, for at least one year. After diagnosing GHD, GH replacement therapy (Humatrope; Eli Lilly, Indianapolis, IN, USA), by subcutaneous injection every day in the evenings, was started. All measurements (see below) were performed twice: the first assessments were performed at baseline, before start of GH replacement therapy and these were repeated after one year of therapy. After the start of GH therapy, GH doses were adjusted every 3 months, targeting serum total insulin-like growth factor (IGF)-I levels within normal gender- and age-related reference values for the healthy population. Maintenance doses were continued once the target dose was reached. All patients received hormone replacement therapies for pituitary deficiencies other than GHD. Ten healthy male volunteers with a normal body weight (mean age 23.4 years, range 20-28 years; mean body mass index (BMI) $21.8 \mathrm{~kg} / \mathrm{m}^{2}$, range $19.7-25.8 \mathrm{~kg} / \mathrm{m}^{2}$ ), who were part of a previous study in which the dynamics of GH secretion were studied (8), were used to obtain normal values for ghrelin.

The study was performed according to the rules of the local ethics committee. All subjects had given informed consent.

\section{Biochemical measurements}

Fasting venous blood samples were drawn between 0800-1000 $\mathrm{h}$ after an overnight fast, and allowed to coagulate for $30 \mathrm{~min}$. Subsequently, sera were separated by centrifugation and frozen at $-20^{\circ} \mathrm{C}$. Ghrelin was measured in one run with a commercially available radioimmunoassay (Phoenix Pharmaceuticals Inc., Belmont, CA, USA; intra-assay CV 5.3\%, interassay CV $13.6 \%)$. In previous experiments, we had observed that ghrelin levels in blood samples assessed without an extraction procedure did not differ from results obtained after one (data not shown) and therefore, the ghrelin assay was used without an extraction procedure. The same method was used by Tschöp et al. ((5), personal communication). Total IGF-I was determined by a commercially available radioimmunoassay (Medgenix Diagnostics, Brussels, Belgium; intra-assay CV 6.1\%, interassay CV 9.9\%). Commercially available assays were also used for measurements of IGF-binding protein (BP)-1 and IGFBP-3 (Diagnostic System Laboratories Inc., Webster, TX, USA; IGFBP-1 intra-assay CV 4.0\%, interassay CV 6.0\%; IGFBP-3 intra-assay CV $1.8 \%$, interassay CV $1.9 \%)$. Serum glucose, total cholesterol, HDL cholesterol and triglyceride levels were determined with standard laboratory methods.

\section{Body composition assessment}

BMI is defined as weight divided by the square of height $\left(\mathrm{kg} / \mathrm{m}^{2}\right)$ and body fat distribution was estimated using the ratio of waist and hip circumferences (WHR) in $\mathrm{cm}$. Skinfold thickness was measured with calipers at the triceps, biceps, subscapular and suprailiac sites 
and for each patient these values were added together to give a sum-of-skinfolds value. Body composition was assessed after an overnight fast by bioelectrical impedance using a portable tetrapolar impedance plethysmograph (Holtain, Dyfed, UK) which introduces a painless signal $(50 \mathrm{kHz}, 800 \mu \mathrm{A})$ to the body of a supine subject. After correct positioning of the patient and the electrodes, the impedance of the body is determined by the low impedance lean compartment and is a function of the specific resistance of lean tissue, the cross-sectional area and the length of the lean compartment. Total body water was calculated from the formula provided by the manufacturer of the body composition analyzer as: total body water $=\left(\left(\right.\right.$ height $^{2} /$ bioelectrical impedance) $\times 0.585)+1.625$. Assuming that fat mass is anhydrous and lean body mass contains $730 \mathrm{~g}$ water $/ \mathrm{kg}$, then: lean body mass $=$ total body water/0.73. Fat mass was calculated from the difference between total body weight and lean body mass. The bioelectrical impedance predicts body composition with an error that is comparable with the error using anthropometric techniques and thus seems to have little or no advantage over simpler and less extensive techniques (9).

\section{Statistical analysis}

The clinical characteristics are presented as means (S.D.). By-group differences were calculated using Mann Whitney tests. The Wilcoxon signed-ranks test was used for differences within the groups before and after GH treatment. Correlations were made by Spearman's correlation coefficient analyses. All statistics were prepared using a commercially available software program (SPSS for Windows, release 9.0; SPSS Inc., USA). Statistical significance was defined as $P<0.05$.

\section{Results}

Before the start of GH replacement therapy, BMI, WHR and sum of skinfolds were increased in the GHD patients in comparison with reference values for the normal healthy Dutch population (see Table 1). In addition, while fat mass was increased, lean body mass and body water were decreased in comparison with reference values provided by the manufacturer of the bioimpedance plethysmograph (Table 1). Furthermore, circulating total IGF-I and IGFBP-3 levels were decreased in comparison with age- and sex-specific reference values for the healthy population (Table 1).

After one year of $\mathrm{GH}$ replacement therapy, all measurements were repeated. The sum of skinfolds, body fat mass and body water had increased significantly, fat mass had decreased significantly and BMI and WHR were not significantly changed by the growth hormone therapy (Table 1).

Before the start of $\mathrm{GH}$ replacement therapy, mean value and range for fasting ghrelin in the GHD subjects tended to be lower in comparison with healthy subjects in the control group although the difference did not reach significance (GHD fasting ghrelin mean $67.8 \mathrm{pmol} / \mathrm{l}$, range $37.6-116.3 \mathrm{pmol} / \mathrm{l}$; control mean $83.8 \mathrm{pmol} / \mathrm{l}$, range $35.4-132 \mathrm{pmol} / \mathrm{l} ; \quad P=0.11$ ). Mean daily $\mathrm{GH}$ dose after one year of $\mathrm{GH}$ treatment was $1.52 \mathrm{IU}(0.51 \mathrm{mg})$, range $0.78-3.0$ IU (0.19$1 \mathrm{mg})$. Ghrelin levels in GHD subjects were not significantly changed in comparison with baseline ghrelin levels obtained before the start of GH therapy (ghrelin before $\mathrm{GH}$ therapy $67.8 \mathrm{pmol} / \mathrm{l}$, range $37.6-$ $116.3 \mathrm{pmol} / \mathrm{l}$; after GH therapy $65.3 \mathrm{pmol} / \mathrm{l}$, range $35.8-112.6 \mathrm{pmol} / \mathrm{l} ; \mathrm{P}=0.56)$. After the year, individual ghrelin levels in this study population were almost unaltered despite significant decreases in sum of skinfolds and fat mass (Fig. 1). However, ghrelin levels in the six subjects with $\mathrm{BMI}>30 \mathrm{~kg} / \mathrm{m}^{2}$ tended to be

Table 1 General characteristics before and after one year of growth hormone replacement therapy. Data shown as means (S.D.): $n=23$.

\begin{tabular}{lccr}
\hline & Before GH therapy & After GH therapy & $\boldsymbol{P}$ value \\
\hline BMI $\left(\mathrm{kg} / \mathrm{cm}^{2}\right)$ & $28.42(2.97)$ & $28.20(2.95)$ & 0.52 \\
WHR & $0.925(0.065)$ & $0.920(0.015)$ & 0.38 \\
Sum of skinfolds $(\mathrm{mm})$ & $91.5(18.4)$ & $80.6(23.9)$ & 0.005 \\
Fat mass $(\mathrm{kg})$ & $34.9(7.4)$ & $31.7(9.2)$ & 0.006 \\
Body fat $(\%)$ & $40.9(7.9)$ & $37.3(9.8)$ & 0.001 \\
Total body water $(\mathrm{l})$ & $37.0(6.9)$ & $39.4(7.2)$ & $<0.001$ \\
Fat free mass $(\mathrm{kg})$ & $50.7(9.5)$ & $53.4(10.5)$ & $<0.001$ \\
Total IGF-I (nmol/l) & $11.2(4.1)$ & $31.9(11.3)$ & $<0.001$ \\
IGFBP-1 (nmol//) & $0.98(0.70)$ & $0.70(0.50)$ & 0.058 \\
IGFBP-3 (nmol//) & $71.7(22.9)$ & $4.55(1.5)$ & $<0.001$ \\
Glucose $(\mathrm{mmol} / \mathrm{l})$ & $4.4(1.4)$ & $5.4(0.8)$ & 0.16 \\
Total cholesterol (mmol/l) & $5.8(1.1)$ & $1.28(0.46)$ & 0.16 \\
HDL cholesterol $(\mathrm{mmol} / \mathrm{l})$ & $1.22(0.45)$ & $1.78(0.89)$ & 0.15 \\
Triglycerides $(\mathrm{mmol} / \mathrm{l})$ & $1.80(0.85)$ & & 0.80 \\
\hline
\end{tabular}

BMI, body mass index; WHR, waist to hip circumference ratio. 


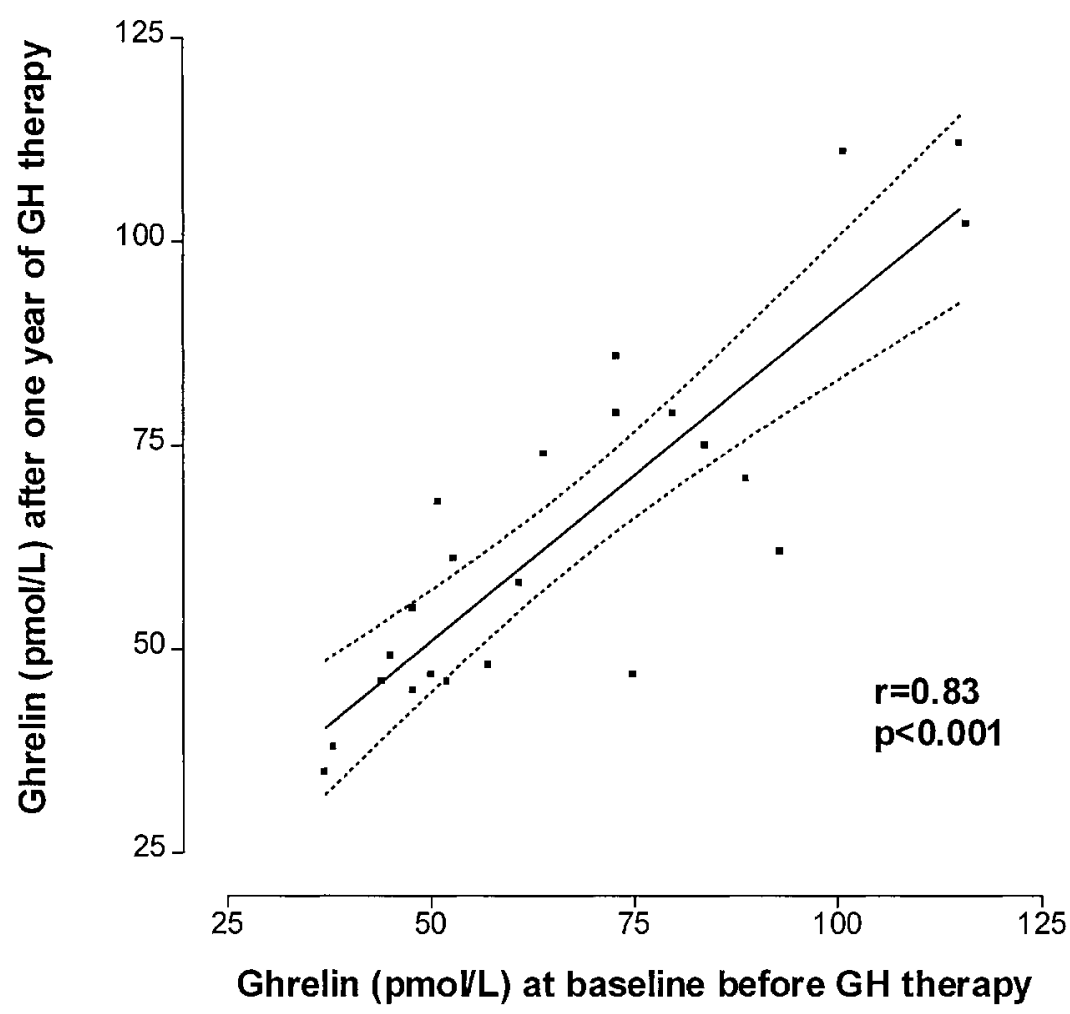

Figure 1 Individual fasting circulating ghrelin levels before and after one year of GH replacement therapy in $23 \mathrm{GH}$ deficient subjects. Almost no change was observed. The dotted lines show the calculated $95 \%$ confidence intervals on the regression line. higher than those in subjects with BMI $<30 \mathrm{~kg} / \mathrm{m}^{2}$. Fasting baseline serum levels of ghrelin were not correlated with body weight $(r=-0.30, P=0.16)$, BMI $(\mathrm{r}=0.10, P=0.64)$, WHR $(\mathrm{r}=-0.28, P=0.20)$, percentage body fat $(\mathrm{r}=-0.36, P=0.09)$, fat mass $(\mathrm{r}=0.25, P=0.24)$, glucose $(\mathrm{r}=-0.18, P=0.41)$ or age $(r=0.19, P=0.40)$. There were also no significant correlations between serum ghrelin levels and any of these parameters after $\mathrm{GH}$ replacement therapy (data not shown).

\section{Discussion}

Contrary to our expectations, baseline circulating ghrelin levels were not elevated in GHD subjects compared with healthy controls. After the start of GH therapy, no lowering of circulating ghrelin levels was observed in the GHD subjects.

At first glance, our study suggests that systemic ghrelin does not have an important role in the development of obesity in GHD subjects and that GH replacement therapy does not modulate systemic ghrelin levels.

There are several data in the literature which agree with the results obtained here. Locatelli and coworkers have shown that, in rats, GHD does not modify ghrelin mRNA expression in the hypothalamus (4). In addition, Tschöp et al. have reported that, fasting ghrelin levels are decreased in obese subjects and are negatively correlated with percentage body fat and fasting insulin (10).
So it is conceivable that the lack of ghrelin modifications after long-term GH therapy is due to the reduction of adiposity and insulin on one hand and increased GH secretion on the other. However, before such conclusions can be drawn, the shortcomings of our study must be discussed.

An important shortcoming of our study was that the lean control group was not age- and sex- matched for the GHD subjects. In addition, circulating ghrelin levels were only measured in the fasting state and in the morning. Recent studies have reported that circulating ghrelin levels are influenced by acute and chronic feeding states in humans $(11,12)$. It could be that decreases in circulating ghrelin levels after feeding are less marked in GHD subjects than in healthy subjects. However, to date, no information is available as to whether changes in circulating ghrelin levels over the day are different in GHD subjects in comparison with healthy subjects. Although all studied individuals were on stable and optimized pituitary hormone replacement therapies, it is not known whether other pituitary hormone deficiencies and/or chronic pituitary hormone replacement therapy have effects on circulating ghrelin levels.

Only octanoylated-ghrelin is reported to be biologically active and it has been suggested that the non-octanoylated form has no biological activity (13). It is presently unknown what percentage of circulating ghrelin is octanoylated (biologically active) and it is also unknown if this percentage is increased in 
human GHD subjects. The ghrelin assay used in our study detects total ghrelin (octanoylated and non-octanoylated), cannot discriminate between the two forms and therefore, changes in octanonylated (biologically active) ghrelin may have been missed. This may have masked the exact relationship between circulating ghrelin levels and the development of obesity in GHD here.

In this study, no significant change in circulating ghrelin levels was observed after one year of treatment with GH. This suggests that GH does not modulate circulating ghrelin levels. However, in the GHD subjects, $\mathrm{GH}$ levels were practically zero in the morning hours when somatropin had been administered the previous evening. In addition, although the exact half-life of circulating ghrelin is not known, several studies suggest that it is less than an hour $(14,15)$ and, as blood was sampled more than eight hours after $\mathrm{GH}$ administration, important changes in circulating ghrelin levels could have been missed.

Human GHD is characterized by an increase in fat mass. In our study, a significant decrease in fat mass was observed after one year of GH treatment. GH has profound effects on body composition through its anabolic and lipolytic effects (16). Conversely, animal studies suggest that ghrelin may induce obesity (5) and ghrelin-induced obesity is probably mediated by hypothalamic regulatory centers. In a study by Tschöp et al., very low doses of ghrelin (administered intracerebro-ventricularly, in a dose 1000-fold less than that used for the experiments studying the effects of peripheral ghrelin administration) induced a significant increase in body weight (5). This animal study suggests that even very small amounts of ghrelin at the hypothalamic level are sufficient to stimulate the development of obesity. Dose-response studies examining the effects of GHRH indicate that femtomole quantities of $\mathrm{GHRH}$ in the brain are also sufficient to influence feeding (17). Circulating systemic ghrelin levels, as measured in our study, are in the range of $30-130 \mathrm{pmol} / \mathrm{l}$ and were thus a 1000-fold higher than the concentrations at which GHRH exerts biological effects in the hypothalamic region. If only a very small amount of ghrelin is able to stimulate food intake, systemic ghrelin levels could have direct actions on hypothalamic centers controlling food consumption. On the other hand, this opens the possibility that small decreases in circulating ghrelin levels during GH replacement therapy could be enough to induce a significant loss of adiposity. However, the only commercially available ghrelin assay in the world to date, as used here, is not sensitive enough to detect such small differences in circulating ghrelin levels and this could have blurred the exact relationship between obesity and circulating ghrelin levels in this study.

Recently, Tschöp and co-workers reported that systemic ghrelin levels were significantly lower in obese subjects (mean BMI $38.2 \mathrm{~kg} / \mathrm{m}^{2}$ ) versus normal lean controls (mean BMI $25.4 \mathrm{~kg} / \mathrm{m}^{2}$ ) (10). Within our GHD patient group, the highest ghrelin levels were found in the subgroup $(n=6)$ with the highest BMI. Interestingly, mean body fat percentage in the GHD group was $41 \%$, while in the obese study group of the report by Tschöp et al., mean body fat percentage was $35 \%$ (10). This would suggest that ghrelin could have direct, $\mathrm{GH}$ independent effects on body composition. In a study by Muller and co-workers, direct, GH independent effects of the GH-secretagogue GH-releasing peptide-6 (GHRP-6) were found in normal individuals pretreated with the $\mathrm{GH}-$ receptor antagonist pegvisomant (8). Tschöp et al. suggested that ghrelin is downregulated in human obesity (10). Our study, however, suggests that in obese GHD subjects, ghrelin levels are less downregulated with increasing body mass. This, again, still leaves open a role for ghrelin in inducing obesity in GHD subjects.

In conclusion, we did not observe elevated ghrelin levels in GHD subjects and GH replacement therapy did not modify circulating ghrelin levels after one year despite significant decreases in body fat mass and percentage body fat. It could be that the lack of ghrelin modifications after long-term $\mathrm{GH}$ therapy is due to a reduction in adiposity and insulin on one hand or to an increase in $\mathrm{GH}$ secretion on the other. However, it is still possible that systemic ghrelin is involved in the development of obesity, both in normal and in GHD subjects. The shortcomings of our study may have masked the real relationships between ghrelin and obesity in these GHD subjects.

\section{Acknowledgement}

The study was supported by an unrestricted grant from Eli Lilly, Nieuwegein, The Netherlands.

\section{References}

1 Kojima M, Hosoda H, Date Y, Nakazato M, Matsuo H \& Kangawa $\mathrm{K}$. Ghrelin is a growth-hormone-releasing acylated peptide from stomach. Nature $1999 \mathbf{4 0 2} 656-660$.

2 Dieguez C \& Casanueva FF. Ghrelin: a step forward in the understanding of somatotroph cell function and growth regulation. European Journal of Endocrinology 2000142 413-417.

3 Wright JC \& Bartke A. Ghrelin administration decreases insulin secretion in Ames dwarf mice. 83rd Annual Meeting of the Endocrine Society, Denver, USA, 2001, Abstract P1-98.

4 Locatelli V, Torsella A, Scibona B, Avallone R, Bresciani E, Deghengi R et al. Expression of ghrelin mRNA in the CNS and peripheral organs of GH-deficient, diabetic or aged rats. 11th International Congress of Endocrinology (ICE), Sydney, Australia, 2000, Abstract P502.

5 Tschöp M, Smiley DL \& Heiman ML. Ghrelin induces adiposity in rodents. Nature $2000 \mathbf{4 0 7} 908-913$.

6 Shintani M, Ogawa Y, Ebihara K, Aizawa-Abe M, Miyanaga F, Takaya K et al. Ghrelin, an endogenous growth hormone secretagogue, is a novel orexigenic peptide that antagonizes leptin action through the activation of hypothalamic neuropeptide Y/Y1 receptor pathway. Diabetes $200150227-232$.

7 Lall S, Jansson J-O \& Dickson SL. Effects of the growth hormone secretagogue (GHS), ipamorelin, on body weight gain in the 
growth hormone deficient lit/lit mice. 11th International Congress of Endocrinology (ICE), Sydney, Australia, 2000, Abstract P412.

8 Muller AF, Janssen JA, Hofland LJ, Lamberts SW, Bidlingmaier M, Strasburger CJ et al. Blockade of the growth hormone (GH) receptor unmasks rapid GH-releasing peptide-6-mediated tissue-specific insulin resistance. Journal of Clinical Endocrinology and Metabolism 200186 590-593.

9 Deurenberg P, van der Kooy K, Leenen R, Weststrate JA \& Seidell JC. Sex and age specific prediction formulas for estimating body composition from bioelectrical impedance: a cross-validation study. International Journal of Obesity 199115 17-25.

10 Tschöp M, Devanarayan V, Weyer C, Tataranni PA, Ravussin E \& Heiman ML. Circulating ghrelin levels are decreased in human obesity. Diabetes $2001 \mathbf{5 0} 707-709$.

11 Tschöp M, Wawarta R, Riepl RL, Friedrich S, Bidlingmaier M, Landgraf $\mathrm{R}$ et al. Post-prandial decrease of circulating human ghrelin levels. Journal of Endocrinological Investigations 200124 $19-21$.

12 Ariyasu H, Takaya K, Tagami T, Mori K, Komatsu Y, Ogawa Y et al. Plasma ghrelin levels are influenced by acute and chronic feeding states in humans. 83rd Annual Meeting of the Endocrine Society, Denver, USA, 2001, Abstract P2-199.

13 Korbonits M, Bustin SA, Kojima M, Jordan S, Adams EF, Lowe DG et al. The expression of the growth hormone secretagogue receptor ligand ghrelin in normal and abnormal human pituitary and other neuroendocrine tumors. Journal of Clinical Endocrinology and Metabolism $200186881-887$.

14 Cummings DE, Purnell JQ, Frayo RS, Schmidova K, Wisse BE \& Weigle DS. A preprandial rise in plasma ghrelin levels suggests a role in meal initiation in humans. Diabetes 200150 1714-1719.

15 Nagaya N, Kojima M, Uematsu M, Yamagishi M, Hosoda H, Oya H et al. Hemodynamic and hormonal effects of human ghrelin in healthy volunteers. American Journal of Physiology 2001280 R1483-R1487.

16 Binnerts A, Swart GR, Wilson JH, Hoogerbrugge N, Pols HA, Birkenhager JC \& Lamberts SW. The effect of growth hormone administration in growth hormone deficient adults on bone, protein, carbohydrate and lipid homeostasis, as well as on body composition. Clinical Endocrinology 199237 79-87.

17 Vaccarino FJ, Kennedy SH, Ralevski E \& Black R. The effects of growth hormone-releasing factor on food consumption in anorexia nervosa patients and normals. Biological Psychiatry 1994 $35446-451$.

Received 23 July 2001

Accepted 21 August 2001 